\title{
Artikel
}

\section{Samenloop bewind en insolventie deelgenoot bij de verdeling van een gemeenschap}

Prof. dr. S. Perrick*

\section{Inleiding en plan van behandeling}

In de praktijk speelt met enige regelmaat de vraag hoe de bevoegdheden van een bewindvoerder in een testamentair bewind of een meerderjarigenbewind zich verhouden tot de bevoegdheden van een bewindvoerder in een schuldsanering die ten aanzien van de rechthebbende is uitgesproken onderscheidenlijk de curator in een faillissement van de rechthebbende. Deze kwestie speelt in het bijzonder bij de verdeling van de gemeenschap waarin de failliet of saniet deelgenoot is. De mij bekende rechtspraak komt naar mijn mening tot evident onjuiste oordelen. Ik motiveer dat in paragraaf 6 .

Ik zal deze vraag beantwoorden nadat ik eerst in paragraaf 2 in het kort aandacht heb besteed an de verdeling waaraan een deelgenoot deelneemt op wiens aandeel in de gemeenschap een bewind rust en in paragraaf 3 de verdeling van een gemeenschap waarvan een van de deelgenoten een failliet of saniet is, onder ogen heb gezien. Alvorens ik in paragraaf 6 toekom aan de centrale vraag behandel ik in paragraaf 4 de wijze van verdeling zowel in het geval een aandeel van een deelgenoot onder bewind staat als in het geval een deelgenoot failliet of saniet is. Over de wijze van verdeling in geval van bewind bestaat verwarring; vandaar dat ik daar dieper op inga. Om de overtuigingskracht van mijn argumenten te vergroten, is het wenselijk dat ik in paragraaf 5 aangeef hoe de wetgever in het algemeen de samenloop

* Prof. dr. S. Perrick is advocaat te Amsterdam. tussen bewind enerzijds en faillissement en schuldsanering anderzijds heeft geregeld.

\section{Verdeling en bewind over aandeel deelgenoot}

Ik besteed allereerst aandacht aan het testamentair bewind over een erfdeel en behandel eerst een testamentair bewind dat is ingesteld in het belang van de deelgenoot/rechthebbende. In het geval de erflater de bevoegdheden van de bewindvoerder niet op de voet van artikel 4:171 van het Burgerlijk Wetboek (BW) heeft uitgebreid of beperkt, is noch de bewindvoerder, noch de deelgenoot zelfstandig bevoegd om aan de verdeling van de gemeenschap mee te werken. Het meewerken door de deelgenoot aan de verdeling is een handeling als bedoeld in artikel 4:167 lid $1 \mathrm{BW}$, dat wil zeggen een andere handeling dan, kort omschreven, een beheershandeling. Dat betekent dat de deelgenoot, indien het bewind in zijn belang is ingesteld, slechts met medewerking of toestemming van de bewindvoerder bevoegd is aan de verdeling mee te werken. Zie artikel 4:167 lid 1 BW. Op grond van artikel 4:169 lid 1 BW mag de bewindvoerder met toestemming van de deelgenoot aan de verdeling meewerken. Deze toestemming van de deelgenoot kan op grond van artikel 4:169 lid 3 BW desverzocht door de kantonrechter worden vervangen door zijn machtiging. Artikel 4:170 lid $2 \mathrm{BW}$ bepaalt dat indien goederen die onder bewind staan tot een gemeenschap behoren, de bewindvoerder met toestemming van de rechthebbende bevoegd is tot medewerking aan de verdeling. Uit deze bepaling mag niet worden afgeleid dat niet ook de deelgenoot aan de verdeling mag meewerken; hij heeft daarvoor, zoals ik hiervoor vermeldde, 
op grond van artikel 4:167 lid $1 \mathrm{BW}$ wel de medewerking of toestemming van de bewindvoerder nodig.

Is het testamentair bewind ingesteld in het gemeenschappelijk belang van de deelgenoten of in het belang van een ander, bijvoorbeeld een vruchtgebruiker, dan zijn de deelgenoten slechts met medewerking of toestemming van de bewindvoerder bevoegd tot de verdeling van een gemeenschappelijk goed. Uit artikel 4:170 lid 2 BW volgt dat artikel 4:167 lid 2 BW niet van toepassing is. Volgens artikel 4:167 lid $2 \mathrm{BW}$ is de rechthebbende, indien het bewind is ingesteld in het belang van een ander dan de rechthebbende of in een gemeenschappelijk belang, slechts onder voorbehoud van het bewind bevoegd tot het verrichten van een andere handeling dan, kort gezegd, een beheershandeling. Zou deze bepaling in geval van verdeling van toepassing zijn, dan zouden onder meer in geval van een bewind in het gemeenschappelijk belang van de deelgenoten, de deelgenoten de gemeenschappelijke goederen 'onder voorbehoud van het bewind' kunnen verdelen zonder medewerking of toestemming van de bewindvoerder, hetgeen uiteraard volledig in strijd met de strekking van het bewind zou zijn. ${ }^{1}$

Heeft de erflater op de voet van artikel 4:171 BW aan de bewindvoerder de bevoegdheid toegekend om de onder bewind gestelde goederen zelfstandig te verdelen, dan is voor de verdeling door de bewindvoerder de toestemming van de deelgenoten niet vereist. Het zal in dat geval vaak gaan om een bewind in het gemeenschappelijk belang van de deelgenoten. Ook indien de erflater over het erfdeel van een deelgenoot in zijn belang een bewind heeft ingesteld, kan hij aan de bewindvoerder de bevoegdheid toekennen om zonder toestemming van de deelgenoot aan de verdeling mee te werken.

Gaat het om een meerderjarigenbewind van afdeling 1.19 , dan is de bewindvoerder tot de verdeling bevoegd, maar hij behoeft daartoe wel de toestemming van de deelgenoot of de machtiging van de kantonrechter. Dit volgt uit artikel 1:441 lid 4 tweede zin BW. Uit deze bepaling volgt naar mijn mening niet dat niet ook de deelgenoot bevoegd is met medewerking van de bewindvoerder of machtiging van de kantonrechter aan de verdeling mee te werken.

\section{Verdeling en deelgenoot die failliet of saniet is}

De failliet wordt bij de verdeling vertegenwoordigd door de curator, die daarvoor de toestemming van de rechter-commissaris nodig heeft. De verdeling maakt onderdeel uit van de vereffening van de failliete boedel.

1. Zie Asser/Perrick 3-V 2019/140
Ook voordat de insolventie is ingetreden, is de curator daartoe bevoegd. ${ }^{2}$

Voor de saniet geldt grosso modo mutatis mutandis hetzelfde. In het hiernavolgende besteed ik daarom niet afzonderlijk aandacht aan de deelgenoot wiens erfdeel in een schuldsanering is betrokken. ${ }^{3}$

\section{Wijze waarop de verdeling plaatsvindt}

Volgens artikel 3:183 lid 1 BW kan de verdeling geschieden op de wijze en in de vorm die partijen goeddunkt, mits de deelgenoten en zij wier medewerking is vereist, onder wie een beperkt gerechtigde op een aandeel in een gemeenschappelijk goed, allen het vrije beheer over hun goederen hebben en in persoon of bij een door hen aangewezen vertegenwoordiger meewerken, dan wel in geval van bewind over hun recht worden vertegenwoordigd door de bewindvoerder voorzien van de daartoe vereiste toestemming of machtiging. In andere gevallen dan in artikel 3:183 lid $1 \mathrm{BW}$ omschreven, moet, tenzij de rechter anders bepaalt, de verdeling geschieden bij notariële akte en worden goedgekeurd door de kantonrechter die bevoegd is de wettelijke vertegenwoordiger van degene die het vrije beheer over zijn goederen mist, tot beschikkingshandelingen te machtigen.

Om met het eenvoudigste te beginnen. De failliet mist het vrije beheer over zijn vermogen. Dat betekent dat de verdeling waaraan de curator namens de failliet deelneemt bij notariële akte dient plaats te vinden. Een redelijke toepassing van artikel 3:182 lid $2 \mathrm{BW}$ in dit geval brengt mee dat de rechter-commissaris en niet de kantonrechter het ontwerp van de akte van verdeling dient goed te keuren, en dat ook de rechter-commissaris bevoegd is te bepalen dat de verdeling niet bij notariële akte behoeft te geschieden en dat de conceptakte niet door de rechter-commissaris behoeft te worden goedgekeurd. De toestemming van de rechter-commissaris is ook dan vereist voor de verdeling. ${ }^{4}$

Ten aanzien van bewind bestaat in de literatuur enige verwarring over de betekenis en toepassing van artikel 3:183 BW. Naar mijn mening kan de verwarring, waarover zo dadelijk meer, op eenvoudige wijze worden weggenomen indien de juiste onderscheidingen worden gemaakt. Qui bene distinguit, bene docet. De eerste onderscheiding die moet worden gemaakt, is of een bewind over goederen van een rechthebbende ertoe leidt dat deze het vrije beheer mist. Dat is bij een testamentair

2. Zie daarvoor uitgebreider S. Perrick, Insolventie en erfrecht, in: G.H Lankhorst e.a., Insolventierecht in de notariële praktijk (KNB preadviezen 2011), Den Haag: Sdu Uitgevers 2011/4.9.2.1.

3. Zie art. $313 \mathrm{Fw}$ op grond waarvan onder meer art. 60a Fw van overeenkomstige toepassing is. Zie ook art. 347 Fw, waarover Perrick, Insolventie en erfrecht, nr. 4.9.2.1.

4. Zie Asser/Perrick 3-V 2019/145 en Perrick, Insolventie en erfrecht, nr. 4.9.3.1. 
bewind niet het geval. ${ }^{5} \mathrm{Bij}$ een meerderjarigenbewind ${ }^{6}$ moet worden onderscheiden al naar gelang alle goederen die aan de rechthebbende toebehoren of zullen toebehoren, waaronder het aandeel in de gemeenschap, dan wel slechts sommige goederen, waaronder eventueel het aandeel in de gemeenschap, onder bewind staan. ${ }^{7}$ In het eerste geval dient de verdeling bij notariële akte te geschieden en te worden goedgekeurd door de kantonrechter. De bevoegde kantonrechter is de kantonrechter die op grond van artikel 1:441 lid $4 \mathrm{BW}$ bevoegd is an de bewindvoerder machtiging voor de verdeling te geven.

Mist de deelgenoot op wiens aandeel een bewind rust niet het vrije beheer, dan dient bij de beantwoording van de vraag of artikel 3:183 lid 2 BW moet worden nageleefd, een aantal gevallen te worden onderscheiden. Het is belangrijk voorop te stellen dat indien de deelgenoot bij de verdeling wordt vertegenwoordigd door een bewindvoerder, er sprake is van een vertegenwoordiger die niet door de deelgenoot is aangewezen. Met andere woorden: ook als artikel 3:183 lid $2 \mathrm{BW}$ niet behoeft te worden nageleefd omdat de deelgenoot het vrije beheer over zijn goederen heeft, is deze bepaling in beginsel desalniettemin van toepassing omdat de deelgenoot wordt vertegenwoordigd door een niet door hem angewezen vertegenwoordiger. Op dit beginsel maakt de wet een uitzondering indien de deelgenoot wordt vertegenwoordigd door de bewindvoerder, voorzien van de daartoe vereiste toestemming of machtiging. Dit betekent dat de verdeling vormvrij is en dat derhalve geen concept van de eventuele notariële akte van verdeling behoeft te worden goedgekeurd door de in artikel 3:183 lid $2 \mathrm{BW}$ bedoelde kantonrechter indien de bewindvoerder is voorzien van de vereiste toestemming van de rechthebbende of vervangende machtiging van de kantonrechter. Dat de door de wetgever gemaakte uitzondering redelijk is, blijkt ook indien wij onder ogen zien op welke wijze de verdeling dient plaats te vinden indien de deelgenoot zelf aan de verdeling deelneemt. Zoals in paragraaf 2 door mij is aangenomen, staat artikel 4:170 lid 2 BW er niet aan in de weg dat de deelgenoot aan de verdeling deelneemt. Deze heeft daarvoor op grond van artikel 4:167 lid 1 BW de medewerking of toestemming van de bewindvoerder nodig, die niet kan worden vervangen door een machtiging van de kantonrechter. Artikel 3:183 BW is niet van toepassing. Immers, de deelgenoot mist niet het vrije beheer over zijn goederen en hij werkt in persoon mee aan de verdeling. Dus ook in dit geval is de verdeling vormvrij en behoeft een eventuele notariële akte niet door de kantonrechter te worden goedgekeurd.

5. M.J.A. van Mourik \& F.W.J.M. Schols, Gemeenschap (Monografieën BW, nr. B9), Deventer: Wolters Kluwer 2015/64 lijkt ten onrechte te menen dat iemand ook het vrije beheer over zijn goederen mist als uitsluitend zijn aandeel in de gemeenschap onder bewind is gesteld.

6. En ook in geval van een bewind over het vermogen van een afwezige dat volgens art. 1:409 BW zowel over het geheel als over een gedeelte van de goederen van de afwezige kan worden ingesteld.

7. Dit onderscheid maakt M.J.A. van Mourik \& L.C.A. Verstappen, Handboek Nederlands vermogensrecht bij scheiding. Algemeen deel A, Deventer: Kluwer 2014/5.8.13 niet.
Wat betekent deze constatering voor het geval de erflater de bewindvoerder, bijvoorbeeld bij een afwikkelingsbewind, op de voet van artikel 4:171 BW zelfstandig bevoegd heeft verklaard aan de verdeling mee te werken? Dan is de bewindvoerder bevoegd aan de verdeling mee te werken zonder toestemming van de rechthebbende of (vervangende) machtiging van de kantonrechter. Volgens de tekst van artikel 3:183 lid $1 \mathrm{BW}$ is artikel 3:183 lid $2 \mathrm{BW}$ dan van toepassing. Maar dat zou tot het ongerijmde resultaat leiden dat indien de bewindvoerder aan de verdeling meewerkt zonder de op grond van artikel 4:170 lid 3 in verbinding met artikel 4:169 lid 3 $\mathrm{BW}$ vereiste toestemming van de deelgenoot, dan wel de vervangende machtiging van de kantonrechter omdat de bewindvoerder de toestemming of machtiging niet behoeft en deze dus ontbreekt, de verdeling bij notariële akte dient plaats te vinden en dient te worden goedgekeurd door de kantonrechter. Dit terwijl artikel 4:171 BW het nu juist mogelijk wil maken dat de bewindvoerder zelfstandig, dat wil zeggen zonder toestemming van de rechthebbende en zonder machtiging van de kantonrechter, de verdeling tot stand kan brengen. De conclusie dient naar mijn mening dan ook te zijn dat de verdeling waaraan de bewindvoerder zelfstandig meewerkt omdat hij niet de toestemming van de deelgenoot of de machtiging van de kantonrechter behoeft, vormvrij kan plaatsvinden en dat een eventuele notariële akte van verdeling niet behoeft te worden goedgekeurd door de kantonrechter. In artikel 3:183 lid $1 \mathrm{BW}$ dient als toegevoegd aan 'voorzien van de daartoe vereiste toestemming of machtiging' te worden gelezen 'voor zover vereist'.

\section{Samenloop bewind en insolventie - algemeen}

Alvorens de vraag te kunnen beantwoorden hoe de bevoegdheden van de bewindvoerder in een bewind over het aandeel van een insolvente deelgenoot zich verhouden tot de bevoegdheden van de curator in diens faillissement, dient eerst aandacht te worden besteed aan artikel 60a van de Faillissementswet $(\mathrm{Fw}){ }^{8}$ Uitgangspunt van artikel $60 \mathrm{a} F \mathrm{w}$ is dat de faillissementscurator het bewind dient te erkennen. Op dat beginsel maakt artikel 60a lid $1 \mathrm{Fw}_{\mathrm{w}}$ een uitzondering voor een specifiek geval. Volgens artikel 60a lid $1 \mathrm{Fw}$ dient de curator de goederen van de bewindvoerder op te eisen indien zich schuldeisers ter verificatie hebben aangemeld die deze goederen onbelast met het bewind kunnen uitwinnen. Door de opeising van een goed door de curator eindigt het bewind over dat goed.

Bij een testamentair bewind bepaalt artikel 4:175 lid 1 BW voor welke schulden de onder bewind staande goederen vrij van bewind kunnen worden uitgewonnen.

8. Dat per 1 januari 1992 is ingevoerd tegelijkertijd met de invoering van de Boeken 3, 5 en 6 NBW. 
Daarbij zijn in het bijzonder de schulden van de nalatenschap van belang. Bij een bewind op de voet van afdeling 1.19 blijken deze schulden uit artikel 1:440 BW. Indien het gaat om een nalatenschap met één erfgenaam die failliet is, zal, ervan uitgaande dat de curator de nalatenschap niet heeft verworpen maar heeft aanvaard onder het voorrecht van boedelbeschrijving, ${ }^{9}$ de nalatenschap overeenkomstig afdeling 4.6.3 worden vereffend. Omdat de failliete erfgenaam op grond van artikel 4:206 lid 5 BW niet als vereffenaar kan optreden, zal zich de situatie voordoen dat de rechtbank een vereffenaar heeft benoemd. De testamentaire bewindvoerder over het erfdeel van de failliete erfgenaam en de rechthebbende (lees: de curator) mogen het beheer en de vereffening door de vereffenaar niet doorkruisen zolang de vereffening voortduurt. ${ }^{10}$ Dit betekent dat de curator in dit geval niet bevoegd is goederen van de nalatenschap van de bewindvoerder op te eisen, althans dat de bewindvoerder niet bevoegd is dit verzoek in te willigen. Zo al voldaan zou zijn aan de voorwaarde dat zich schuldeisers van de nalatenschap ter verificatie bij de curator hebben aangemeld. Deze schuldeisers hebben daar geen belang bij, want zij kunnen hun vorderingen bij de vereffenaar indienen, terwijl de failliete erfgenaam niet verplicht is deze schulden ten laste van zijn overig vermogen te voldoen nu de nalatenschap namens hem is aanvaard onder het voorrecht van boedelbeschrijving. Zie artikel 4:184 lid 2 aanhef en onder a BW. Zou de curator wel bevoegd zijn om op de voet van artikel 60a lid $1 \mathrm{Fw}$ onder bewind staande goederen op te eisen, dan zou het gevolg van die opeising zijn dat het bewind over de opgeëiste goederen is geëindigd. $\mathrm{Nu}$ de curator in dit geval niet tot opeising van onder bewind staande goederen bevoegd is, blijven de onder bewind staande goederen buiten het faillissement. Zie artikel 60a lid 3 en artikel $21 \mathrm{Fw}$. Hierbij merk ik op dat artikel 60a lid 2 $\mathrm{F}_{\mathrm{w}}$ als niet geschreven dient te worden beschouwd, omdat deze bepaling het lot van artikel 4:176 BW deelt. ${ }^{11}, 12$

Volledigheidshalve zie ik ook onder ogen het geval dat de insolvente erfgenaam op het tijdstip dat de nalatenschap openvalt nog niet failliet is verklaard en hij de nalatenschap zuiver heeft aanvaard. Ook dan zal de nalatenschap overeenkomstig afdeling 4.6.3 worden vereffend. De schuldeisers van de nalatenschap zullen er immers belang bij hebben dat de rechtbank op grond van artikel 4:204 lid 1 aanhef en onder b BW een vereffenaar benoemt. Op die manier kan het vermogen van de nalatenschap worden afgescheiden van de privéschuldeisers van de failliete erfgenaam. Ook dan mag de bewindvoerder het beheer en de vereffening door de vereffenaar niet doorkruisen. Dan kan zich (theoretisch)

9. Zie art. 41 lid $1 \mathrm{Fw}$, dat in art. $313 \mathrm{Fw}$ van overeenkomstige toepassing wordt verklaard op de schuldsaneringsregeling natuurlijke personen.

10. Zie Asser/Perrick 4 2017/675.

11. Zie Asser/Perrick 4 2017/757. J.W.A. Biemans, Bewind en insolventie, WPNR 2015/7064, p. 494-498 onderschrijft mijn opvatting.

12. Ook de passage van de laatste zin van art. $60 \mathrm{a}$ lid $1 \mathrm{Fw}$, die begint met 'tenzij', dient als niet geschreven te worden beschouwd. het geval voordoen dat een schuldeiser van de nalatenschap zijn vordering ter verificatie aanmeldt bij de na het openvallen van de nalatenschap benoemde curator, maar hij zal daar geen belang bij hebben. Ten behoeve van hem is immers het vermogen van de solvabele nalatenschap afgescheiden. En de curator is niet bevoegd eventueel na de voldoening van de schuldeisers van de nalatenschap resterende goederen van de nalatenschap op te eisen ten behoeve van privéschuldeisers van de failliet die zich ter verificatie hebben aangemeld. Dat zijn immers niet schuldeisers die de onder bewind staande goederen onbelast met het bewind kunnen uitwinnen. Op deze resterende goederen dient het bewind te blijven rusten.

En indien de nalatenschap niet geheel solvabel mocht zijn, zijn er ook geen met bewind belaste goederen die door de curator kunnen worden opgeëist. In dat geval zal de vereffening immers niet eindigen met een met bewind belast overschot. Er valt voor de curator dan dus niets op te eisen van de bewindvoerder.

Men realisere zich overigens dat er bij een meerderjarigenbewind een grotere kans is dat de curator met recht onder bewind gestelde goederen opeist. De onder bewind staande goederen kunnen volgens artikel 1:440 BW immers onder meer worden uitgewonnen voor schulden van de rechthebbende die zijn ontstaan voordat zijn goederen onder bewind waren gesteld. Het feit dat de nalatenschap namens de erfgenaam beneficiair is aanvaard, en deze derhalve overeenkomstig afdeling 4.6.3 wordt vereffend, staat er niet aan in de weg dat de schuldeisers die zich op grond van artikel 1:440 BW kunnen verhalen op de onder bewind staande goederen hun vorderingen ter verificatie bij de curator aanmelden. De curator kan dan met recht de met bewind belaste goederen opeisen, voor zover dit voor de voldoening van deze schuldeisers uit de opbrengst nodig is, met als gevolg dat het bewind over deze goederen eindigt. Naar mijn mening kan de curator dat eerst doen nadat de vereffening van de nalatenschap is afgerond. Het betreft hier dus de, met bewind belaste, goederen van de nalatenschap die resteren nadat de schuldeisers van de nalatenschap zijn voldaan.

Het is ook overigens eenvoudig aan de hand van een voorbeeld aan te tonen dat de opvatting ${ }^{13}$ dat het bepaalde in de $F_{W}$ voorgaat op het bepaalde in Boek 1 en 4 BW in zijn algemeenheid wel onjuist moet zijn. Voorbeeld. Over het erfdeel van een erfgenaam is een testamentair bewind ingesteld in het belang van de erfgenaam; het bewind heeft de strekking de erfgenaam die met schulden is overbelast tegen zichzelf te beschermen. Het gevolg van dit bewind is dat de onder bewind staande goederen slechts kunnen worden uitgewonnen voor de in artikel 4:175 lid $1 \mathrm{BW}$ omschreven schulden. Dat wil zeggen in beginsel niet voor 'eigen' schulden van de erfgenaam. Indien men zou aannemen dat het onder bewind staande erfdeel en de goederen die geacht moe-

13. Aangehangen door Rb. Maastricht 6 augustus 2018, waarover paragraaf 6 slot. 
ten worden daarvoor in de plaats te treden, zie artikel 4:154 BW, ten gevolge van het faillissement vrij van het bewind in de faillissementsboedel zouden vallen, dan zou dat volledig in strijd zijn met de strekking van dit bewind. Artikel 60a Fw gaat er dan ook van uit dat de onder bewind staande goederen onder het bewind van de bewindvoerder blijven. Zou dit anders zijn, dan zou een bewind met deze strekking betrekkelijk zinloos zijn. Immers, het bewind zou - al dan niet tijdelijk - vervallen met als gevolg dat de onder bewind staande goederen van de rechthebbende op dezelfde voet als de goederen van de rechthebbende die niet onder bewind staan, door de curator te gelde kunnen worden gemaakt teneinde de opbrengst te verdelen onder de schuldeisers van de failliete rechthebbende. Onder wie begrepen de schuldeisers die zich voorafgaande aan het faillissement van de rechthebbende niet op de goederen waarop het bewind rust(te), konden verhalen.

\section{Samenloop bewind en insolventie deelgenoot}

Indien het gaat om een gemeenschap van een nalatenschap waarvan een van de erfgenamen/deelgenoten failliet is en op wiens aandeel een testamentair bewind rust, geldt het in paragraaf 5 opgemerkte mutatis mutandis. Men realisere zich dat indien de curator wel bevoegd is het onder bewind gestelde aandeel in de gemeenschap op te eisen en onder zijn beheer te nemen, de curator het aandeel in de gehele gemeenschap te gelde zal dienen te maken. ${ }^{14}$ Doet zich een geval voor dat de curator het met bewind belaste aandeel in de gemeenschap niet met recht kan opeisen, dan komen in geval van verdeling van de gemeenschap aan de faillissementscurator geen bevoegdheden toe. Het aandeel in de gemeenschap valt immers niet in de faillissementsboedel. De curator zal er overigens geen belang bij hebben met bewind belaste goederen op te eisen van de bewindvoerder. Hij is daartoe slechts bevoegd indien zich een of meer schuldeisers van de nalatenschap hebben aangemeld. Een schuldeiser van de nalatenschap zal daarbij slechts belang hebben voor zover hij niet door de vereffenaar uit de opbrengst van de goederen van de nalatenschap is voldaan. Mocht zich het geval voordoen dat een schuldeiser van de nalatenschap niet volledig kan worden voldaan uit de opbrengst van de goederen van de nalatenschap, dan betekent dit dat er geen goederen van de nalatenschap resteren en er geen met bewind belast aandeel in gemeenschappelijke goederen resteert dat de curator kan opeisen.

Gaat het om een testamentair afwikkelingsbewind, dan geldt hetgeen ik in de vorige alinea als geldend recht heb aangenomen eveneens.

14. Verzet de rechtsverhouding zich ertegen dat de (insolvente) deelgenoot over het aandeel kan beschikken, dan kan de curator dat ook niet te gelde maken. Dat volgt uit art. 3:191 lid 1 BW.
Het feit dat een met een testamentair bewind belast aandeel in de gemeenschap buiten het faillissement blijft, neemt naar mijn mening niet weg dat de failliet het vrije beheer over zijn vermogen mist. En dit betekent dat volgens de tekst van artikel 3:183 lid 2 BW deze bepaling dient te worden nageleefd. Een redelijke wetstoepassing brengt mijns inziens mee dat artikel 3:183 lid 2 $\mathrm{BW}$ in dit geval niet van toepassing is. De deelgenoot is weliswaar failliet en mist uit dien hoofde het vrije beheer over zijn vermogen, maar over het aandeel in de gemeenschap heeft hij met inachtneming van de beperkingen die het bewind over het aandeel meebrengt, nu juist wel het 'vrije beheer'.

In geval van een meerderjarigenbewind geldt hetzelfde. Volgens artikel 1:441 lid 4 tweede zin BW behoeft de bewindvoerder voor het aangaan van de verdeling óf de toestemming van de deelgenoot óf de machtiging van de kantonrechter.

Indien de curator bevoegd is het aandeel in de gemeenschap op de voet van artikel 60a lid $1 \mathrm{Fw}_{\mathrm{w}}$ op te eisen en dat ook daadwerkelijk doet, eindigt het bewind. Dan is er verder geen rol weggelegd voor de bewindvoerder.

Is de curator niet tot opeising van het met bewind belaste aandeel in de gemeenschap bevoegd, en staat vast dat hij niet met recht tot opeising van het aandeel in de gemeenschap zal overgaan, dan is er geen rol weggelegd voor de curator. Het aandeel valt niet in het faillissement en de rechthebbende kan de aan hem toekomende bevoegdheden uitoefenen als ware hij niet failliet. Zolang onduidelijk is of de curator tot opeising van onder bewind gestelde goederen zal overgaan, dient de bewindvoerder de veilige weg te kiezen en ervan uit te gaan dat hij de toestemming van de rechthebbende (lees: de curator) of de vervangende machtiging van de kantonrechter behoeft. De meest praktische weg zal dan zijn het verzoeken van de machtiging van de kantonrechter. Aan deze kantonrechter kan dan tegelijkertijd worden verzocht de verdeling bij notariële akte op de voet van artikel 3:183 lid $2 \mathrm{BW}$ goed te keuren. ${ }^{15}$

Rechtbank Gelderland ${ }^{16}$ miskent dat de bewindvoerder in de schuldsanering het meerderjarigenbewind in beginsel dient te erkennen. Ten onrechte oordeelde Rechtbank Maastricht ${ }^{17}$ dat het bepaalde in de Fw (lex specialis) voorgaat op het bepaalde in Boek 1 en 4 BW (lex generalis). De minister ${ }^{18}$ lijkt artikel 60a $\mathrm{F}_{\mathrm{w}}$ over het hoofd te zien. Hij merkt op dat het beschermingsbewind gedurende de toepassing van de schuldsaneringsregeling beperkt is tot goederen die niet in de boedel vallen.

15. In Insolventie en erfrecht, nr. 4.9.2.2 heb ik onvoldoende duidelijk aangegeven dat het hier om een uitzonderlijke situatie gaat.

16. Rb. Gelderland 16 oktober 2015, ECLI:NL:RBGEL:2015:6529.

17. Rb. Maastricht 6 augustus 2008, Notamail 2008/244.

18. Kamerstukken II 2011/12, 33054, 6, p. 12-13. 


\section{Korte samenvatting}

In dit artikel heb ik onderbouwd dat het uitgangspunt van de $\mathrm{Fw}_{\mathrm{w}}$ is dat de faillissementscurator en de bewindvoerder in een schuldsanering het bewind over goederen van de failliet en de saniet dienen te erkennen. Artikel 60a lid $1 \mathrm{Fw}$ kent aan de faillissementscurator de bevoegdheid toe om in een specifiek geval onder bewind gestelde goederen op te eisen. ${ }^{19}$ Deze mogelijkheid zal in de praktijk van belang zijn in het geval van een bewind op de voet van titel 1.19. Het gevolg van het feit dat de curator met recht een goed waarop een bewind rust opeist, is dat het bewind over dat goed eindigt. Betreft het met bewind belaste goed een aandeel in een gemeenschap, dan heeft het met recht opeisen daarvan tot gevolg dat het bewind over dat aandeel vervalt en uitsluitend aan de curator bevoegdheden met betrekking tot dat aandeel toekomen. Bij de verdeling van een gemeenschap waarvan een aandeel met testamentair bewind is belast, zal de curator in beginsel niet bevoegd zijn met bewind belaste goederen op te eisen. Dat betekent dat aan de curator, aan wie niet het recht toekomt een met bewind belast aandeel in een gemeenschap op te eisen, geen bevoegdheden toekomen bij de verdeling van de gemeenschap. Het met bewind belaste andeel valt dan buiten de faillissementsboedel.

In paragraaf 4 heb ik aandacht besteed aan de wijze waarop artikel 3:183 BW dient te worden toegepast. Dat wil zeggen aan de wijze waarop de verdeling dient plaats te vinden ingeval een deelgenoot failliet is of diens erfdeel onder bewind is gesteld. In paragraaf 6 geef ik aan waartoe een redelijke toepassing van artikel 3:183 BW leidt indien de gemeenschap wordt verdeeld en een van de deelgenoten op wiens aandeel een bewind rust, failliet is. 